\title{
Studies on induced breeding of Clarias gariepinus (Burchell, 1822) in Hapa Pens
}

\author{
*ORJI RAPHAEL, C.A.' AND N.M. INYANG ${ }^{2}$ \\ 1 Department of Fisheries Technology \\ Michael Okpara College of Agriculture, \\ P.M.B. 1472, Owerri, Nigeria \\ 2 Department of Zoology, \\ University of Nigeria, \\ Nsukka, Nigeria
}

\begin{abstract}
Induced breeding of Clarias gariepinus was conducted monthly in hapa pens, set up in Otamiri river for nineteen months (June 1993 - December 1994). Results of natural fertilization were unsatisfactory as few eggs were fertilized. Mean relative fecundity, percentage fertilization, percentage hatching and percentage fry survival were:

$15.86 \pm 1.95 \times 10^{3}, 18.92 \pm 5.28 \%, 13.50 \pm 3.8 \%$ and $6.42 \pm 0.72 \%$. Results from artificial fertilization were as follows: Mean relative fecundity, $13.80 \pm 2.85 \times 10^{3}$, percentage fertilization, $81.91 \pm 2.28 \%$, percentage hatching, $86.10 \pm 2.46 \%$ and percentage fry survival, $21.40 \pm 1.89 \%$ respectively. The success of artificial fertilization depended largely on the latency period of 9-11 hours and this suggests that induced breeding in pens is feasible. The poor results from natural fertilization were attributed to lack of adequate substrate for the male fish to display courtship and subsequent fertilization of eggs.
\end{abstract}

\section{INTRODUCTION}

Different facilities and techniques of pen culture method of spawning catfish have been used (TOOLE, 1951; NELSON, 1957). There has been little interest in induced breeding in pens. Instead, complex high technological indoor and outdoor hatchery facilities have been used. Fry or fingering rearing in pens and cages has been investigated (FAO, 1980; WOYNAROVICH and HORVATH, 1980; FAO, 1983).

Efficient hatchery structures and facilities are expensive and efforts should therefore be channeled towards less expensive alternatives such as cages, pens and net enclosures.

Comparing the advantages of cage culture, pen culture and net enclosure over the conventional pond and tank cultures, OTUBUSIN (1985) stressed that the former systems do not compete with other land uses, e.g. agriculture, urbanization and industry. Further, the systems require limited investments and allow high stocking density of fish and complete control of the harvest. Also, they generally provide high returns on investment when effectively managed with suitable fish species and culture sites. This paper assesses the use of pens in induced breeding of Clarias gariepinus with a view to solving the problem of expensive hatchery structures.

\section{MATERIALS AND METHODS}

Clarias gariepinus broodfish used for this investigation were raised from eggs to maturity in the hatchery and grow-out ponds of the Department of Fisheries Technology of Micheal Okpara College of Agriculture Owerri, Nigeria. Assessment of male and female fish for maturity, extraction of pituitary glands from donors, preparations and injection of pituitary hormones were carried out according to VIVEEN et al (1985). The hapa netting used in constructing the pens is cheap and readily available in Nigeria. It is "cacoflex coated marine mesh" produced by coating. Engineering Corporation (CEC) USA and is polyamide monofilament netting with a mesh size of $0.5 \mathrm{~mm}$ and twine diameter of $0.25 \mathrm{~mm}$. Each pen was sewn in rectangular form $\left(1.5 \times 1.5 \times 1.0 \mathrm{~m}^{3}\right)$ and each corner was tied to a bamboo stick in the Otamiri river. 


\section{Induced Breeding in Hapa Pens by Natural Spawning}

Monthly induced breeding exercises were carried out in two hapa pens for twelve months (June 1993 - May 1994). From June 1994 to December 1994, two sets of hapa pens for both natural spawning and artificial spawning were investigated. For natural spawning, injected male and female spawners were paired. One knock-out injection of homoplastic pituitary was administered for each inducement or the appropriate dosage of $0.33 \mathrm{mg} / 120 \mathrm{~g}$. weight or two glands per fish of equivalent weight. Injections were administered intraperitoneally at the axil of the pectral fins. The hapa pens were initially set up at fast-flowing sites of the river (water current of $0.25 \mathrm{~m} . \mathrm{sec}^{-1}$ and water discharge of $6.48 \mathrm{~m}^{3} \mathrm{sec}^{-1}$ ) for two months-June to July 1993. In August 1993, the pens were transferred to a lentic site where the water was relatively stagnant. From September to October 1993- December 1994, the bases of pens were lowered to rest on the bed of the river. Stability was achieved with the support of pieces of stones at bases of the pens. The transfer of the pens from the fast-flowing site to stagnant sites was necessitated by the male fish to fertilize the female eggs. The lowering of the pens to the bed of the river was to provide a solid substratum for effective courtship and subsequent fertilization of eggs.

\section{Induced Breeding in Hapa Pens by Artificial Fertilization}

Two sets of hapa pens were used to assess induced breeding of $C$. gariepinus by artificial fertilization (June-December 1994). Eggs were obtained by stripping, while the male was cut open to squeeze out the milt from the testes as stripping was not possible due to the testes morphology (CLEMENS and SNEED, 1971). A latency period (period between injection and ovulation) of 9-11 hours was found to be ideal for successful fertilization of eggs. The fertilization solution was $8 \%$ saline. Fertilized eggs were later transferred to the pens, protected by nylon net mesh. Relative fecundity, percentage fertilization, percentage hatching and percentage fry survival were determined according to VIVEEN et al (1985).

\section{RESULTS}

In the fast-flowing part of the river, although the females released eggs, there was no fertilization and consequently no hatching of eggs. After the pens were transferred to the swampy sites and the pens rested on the floor of the river, there was partial fertilization of eggs (Table I). Mean relative fecundity was $15.86 \pm 1.95 \times 10^{3}$, percentage fertilization $18.92 \pm 5.28 \%$, percentage hatching $13.50 \pm 3.87 \%$ and percentage fry survival of $6.42 \pm 0.7 \%$. Using artificial fertilization, mean relative fecundity, percentage fertilization, percentage hatching and percentage fry survival were $13.80 \pm 2.78 \mathrm{x}$ $10^{3}, 81.83 \pm 2.28 \%, 86.07 \pm 2.46 \%$ and 21.36 $\pm 1.87 \%$ (Table 2). Thus successful induced breeding of $C$. gariepinus in hapa pens is possible by artificial fertilization in stagnant sites of river, while successful results are yet to be achieved with natural fertilization. A latency period of 9-11 hours enhanced successful fertilization of eggs.

\section{DISCUSSION}

Results obtained by natural fertilization of eggs were unsatisfactory, even when the hapa pens were transferred to swampy sites. Though eggs were laid, there was no fertilization. Successful induced breeding results in pens have been reported with fish species that spawn in captivity for example carp (HARVEY and HOAR, 1979), channel catfish (CROWFORD, 1958; TOOLE, 1951) and coho salmon (IWAMOTO and HERSHNERGER, 1981). Pen spawning of Chrysichthys nigrodigitatus by EZENWA (1982) was unsuccessful. THOMAS (1981) observed that pen spawning in ponds required more efficient handling of brood fish.

In the present experiment, the only set up which allowed the male to perform its natural courtship and fertilize eggs was that where the hapa pens rested on the river bed.

Successful fertilization by stripping was attributed to an appropriate latency period of 911 hours. Knowledge of the ideal latency period permits a more efficient operation. CLEMENS and SNEED (1971) noted that once the latency period lapsed, no fish continued development to complete ovulation stage, suggesting that absorption of hormones was complete and ovulated eggs became overripe and could not be spawned. More induced breeding research efforts on other local species are recommended. 
Table 1. Monthly Results of Induced Breeding in Pens (June 1993 - May 1994) By Natural Method

\begin{tabular}{|c|c|c|c|c|c|c|c|c|c|}
\hline Months & Sex & $\begin{array}{l}\text { Wet Pituitary } \\
\text { Dosage (mg) }\end{array}$ & $\begin{array}{l}\text { Fish wt. Before } \\
\text { Spawn }(\mathrm{gm})\end{array}$ & $\begin{array}{l}\text { Fish wt. After } \\
\text { Spawn }(\mathrm{gm})\end{array}$ & $\begin{array}{l}\text { Difference } \\
\text { in wt. }\end{array}$ & Fecundity & $\begin{array}{l}\text { Fertilization } \\
\text { (percentage) }\end{array}$ & $\begin{array}{l}\text { Hatch } \\
\text { (percent) }\end{array}$ & $\begin{array}{c}\text { Survival } \\
\text { (percent) }\end{array}$ \\
\hline June & $\mathrm{F}$ & 16.4 & 375 & 358.5 & 16.5 & 11,550 & 0 & 0 & 0 \\
\hline 1993 & $\mathrm{M}$ & 17.5 & 375 & - & - & - & - & - & - \\
\hline July & $\mathrm{F}$ & 8.6 & 120 & 106 & 14 & 9,800 & 0 & 0 & 0 \\
\hline 1993 & $\mathbf{M}$ & 11.15 & 215 & - & - & - & - & - & - \\
\hline August & $\mathrm{F}$ & 11.5 & 175 & 167.5 & 7.5 & 5,250 & 0 & 0 & 0 \\
\hline 1993 & $\mathbf{M}$ & 13.15 & 172.5 & - & - & - & - & - & - \\
\hline September & $\mathrm{F}$ & 12.0 & 212.5 & 202.5 & 10 & 7,000 & 0 & 0 & 0 \\
\hline 1993 & $\mathbf{M}$ & 14.5 & 225 & - & - & - & - & - & - \\
\hline October & $\mathrm{F}$ & 12.2 & 200 & 189.5 & 10.5 & 7,350 & 0 & 0 & 0 \\
\hline 1993 & $\mathrm{M}$ & 15.8 & 225 & - & - & - & - & - & - \\
\hline November & $\mathrm{F}$ & 9.5 & 150 & 136.5 & 13.5 & 9,450 & 30 & 10 & 10 \\
\hline 1993 & $\mathbf{M}$ & 12.5 & 150 & - & - & - & - & - & - \\
\hline December & F & 8.8 & 135 & 131.5 & 3.5 & 2,450 & 0 & 0 & 0 \\
\hline 1993 & $\mathbf{M}$ & 12.9 & 170 & - & - & - & - & - & - \\
\hline January & $F$ & 8.7 & 150 & 0 & 0 & 0 & 0 & 0 & 0 \\
\hline 1993 & $\mathbf{M}$ & 16.15 & - & - & - & - & - & - & - \\
\hline February & $F$ & 8.68 & 150 & 137.5 & 12.5 & 8,750 & 25 & 25 & 8 \\
\hline 1993 & $\mathbf{M}$ & 9.4 & 150 & - & - & - & - & - & - \\
\hline March & $\mathrm{F}$ & 9.9 & 162.5 & 158 & 4.5 & 3,750 & 30 & 25 & 8 \\
\hline 1993 & $\mathbf{M}$ & 14.3 & 235 & - & - & - & - & - & - \\
\hline April & $\mathrm{F}$ & 8.4 & 165 & 150 & 15 & 10,500 & 20 & 12 & 6 \\
\hline 1993 & $\mathrm{M}$ & 10.8 & 200 & - & - & - & - & - & - \\
\hline May & $F$ & 7.5 & 155 & 137.5 & 17.5 & 12,250 & 4 & 4 & 2 \\
\hline 1993 & $\mathrm{M}$ & 12.6 & $250-$ & - & - & - & - & - & - \\
\hline
\end{tabular}


Table 2. Mean Monthly Results of Induced Breeding by Stripping in Pens (June - December 1994)

\begin{tabular}{|c|c|c|c|c|c|c|c|c|c|}
\hline June & $\mathrm{F}$ & 10.4 & 150 & 134 & 16 & 11,200 & 73 & 73 & 3 \\
\hline July & F & 8.1 & 125 & 112 & 13 & 9,100 & 82 & 87 & 18 \\
\hline 1994 & $\mathrm{M}$ & 14.2 & 200 & - & - & - & - & - & - \\
\hline September & $\mathrm{F}$ & 7.6 & 125 & 114 & 11 & 7,700 & 73 & 70 & 17 \\
\hline 1994 & $\mathbf{M}$ & 17.2 & 238 & - & - & - & - & - & - \\
\hline October & $F$ & 12.5 & 200 & 192 & 8 & 5,600 & 78 & 95 & 17 \\
\hline 1994 & $\mathbf{M}$ & 11.8 & 200 & - & - & - & - & - & - \\
\hline November & $\mathrm{F}$ & 10.7 & 200 & 197 & 3 & 2,100 & 83 & 93 & 23 \\
\hline
\end{tabular}




\section{REFERENCES}

Clemens, H.F. and Sneed, K.E. 1971. Bioassay and use of pituitary materials to spawn warm water fish. U.S. Govt. Printing Office:- 1971Q-442-509: J24 30P.

Crowford, B. 1958. Propagation of channel catfish at state fish hachery- Proceedings of the 11th Annual conference, South Eastern Association of Game and Fish Commission, 132-141.

Ezenwa, B. 1982. Hatchery Production of catfish $C$. nigrodigaitatus, Annual Report of Nigerian Institute for Oceanography and Marine Research Lagos 17P.

FAO, 1980. The artificial propagation of warm water fin fish, a manual for extension:- FAO Fisheries Technical Paper No. 38, 26P.

FAO, 1983. Fresh water aquaculture development in China, FAO Fisheries Technical Paper No. $215,47 \mathrm{P}$

Harvey, B. J. and Hoar, W.B., 1979. The theory and practice of induced breeding in fish. IDRCTS 21e 48P

Iwamoto, R.N. and Hershberger, S. 1981. Coho broodstock development for marine net pen culture, 1980 Research in Fisheries, University of Washington, 34P.
Nelson, B. 1957. Propagation of channel catfish in Arkansas:- Proceedings of 10th Annual Conference, Southern- eastern Association of Game and Fish Commission, 165 - 168.

Otubusin, S.O. 1985. Preliminary studies in bamboo floating cage and net enclosure fish culture in Kainji Lake Basin, Proceedings of the Annual Conference of Fisheries Society of Nigeria (FISON) 26-29.

Thomas, C.H. 1951. Catfish farming, USA Dept. of Agriculture Farmer's Bulletin No. 2260:29P

Toole, M. 1951. Channel catfish culture in Texas, Prog. Fish Cult. 13 (1): 3-10.

Viveen, W.J.A.R. Richer, C.J.J., Van- Oordt, P.G.W.J Janssen, A.L and Huisman, E.A. 1985. Pratical manual for the culture of the African catfish, Clarias gariepinus: Directorate General International Cooperation for the Ministry of Foreign Affairs. The Hague, The Netherlands, 5-28.

Woynarovich, E. and Horvath, L. 1980. The artificial propagation of warm water fin fish, a manual for extension, FAO Fisheries Paper No.201, 183P. 